\title{
Relationship Between Sperm DNA Fragmentation and Nuclear Vacuoles
}

\author{
Mariano Lavolpe ${ }^{1}$, Daniela Lorenzi ${ }^{1}$, Ezequiel Greco ${ }^{1}$, Florencia Nodar ${ }^{1}$, Cristian Alvarez Sedó ${ }^{1}$ \\ ${ }^{1}$ Centro de Estudios en Genética y Reproducción (CEGYR) - Buenos Aires, Argentina
}

\begin{abstract}
Objective: The aim of the present study is to assess the correlation between the presence, quantity and size of nuclear vacuoles and DNA damage and chromatin status in sperm samples of men who underwent to assisted reproduction technology.

Methods: Forty six males who underwent to assisted reproductive technology (ART) were considered. According to their latest semen analysis ( $<3$ months), were grouped into: (A) strict morphology index $\leq 4 \%(26)$ and (B) strict morphology index $\geq 14 \%$ (20). Motile sperm were selected by density gradient, and MSOME study was conducted to assess the number and size of nuclear vacuoles. DNA fragmentation (TUNEL) and DNA strand status (acridine orange) were assessed over the selected spermatozoa accordingly to their vacuole pattern.

Results: In group $A$, sperm without vacuoles $\left(1^{\circ}\right)$ have similar levels of DNA fragmentation (TUNEL) in compare to the rest of observed patterns $\left(2^{\circ}-6^{\circ}\right)$. Regarding to $\mathrm{AO}$, spermatozoa with large or several vacuoles that cover more than $30-50 \%$ of the nuclear surface are $\mathrm{AO}+$, but not necessarily TUNEL positive. The first three patterns of vacuoles patterns had lower levels of $A O$ in compare to grades $4^{\circ}$ and $6^{\circ}$. In group $B$, those sperm with one or more vacuoles greater than $30 \%-50 \%\left(4^{\circ}\right.$ and $\left.6^{\circ}\right)$, had a significant increase in TUNEL values, in relation to group $1^{\circ}-3^{\circ}$. Considering $\mathrm{AO}$, it was found that the $4^{\circ}$ and $6^{\circ}$ pattern had a significantly elevated level of this marker, as same of group $\mathrm{A}(P<0.05)$.

Conclusions: There is no relationship between the greater number and size of sperm vacuoles with high levels of DNA fragmentation in patients with severe teratozoospermia (Kruger <4\%). Conversely, this relationship is evident in normal semen samples (normal morphology. Sperm selection by IMSI technique, to select non-fragmented sperm in patients with Kruger $<4 \%$, is not necessarily secured when non-vacuolated sperm is selected.
\end{abstract}

Keywords: DNA fragmentation, Vacuoles, Sperm Morphology.

\section{INTRODUCTION}

Paternal genome integrity is vital to start and maintain a pregnancy. The presence of DNA strand breaks and/or changes in DNA nucleotides (resulting from the paternal genome) in the embryo's genome, is not compatible with normal embryonic and fetal development. Recently it has been shown that sperm DNA fragmentation is a potential cause of unexplained infertility. Likewise, a significant increase in DNA fragmentation levels would be associated with low rates of fertilization, embryo implantation and high rates of miscarriage (Carrell et al., 2003; Seli et al., 2004; Virro et al., 2004; Lewis \& Aitken, 2005; Meseguer et al., 2008; Aitken et al., 2009; Sakkas \& Alvarez, 2010).

Physical and metabolic factors can induce sperm DNA damage. This can occur in spermatogenesis or during the transit through the epididymis (Aitken et al., 2005, Aitken et al., 2006; Aitken \& De Iuliis, 2007; Banks et al., 2005). Furthermore, many risk factors associated to increased
DNA fragmentation have been identified, e.g. varicocele, cryptorchidism, advanced age, severe teratozoospermia, episodes of high fever, radio and chemo therapy (Angelopoulou et al., 2007; Delbes et al., 2007; Smith et al., 2007; Smit et al., 2010; Vagnini et al., 2007; Wu et al., 2009; Moskovtsev et al., 2009; Mehdi et al., 2009).

DNA damage could be single and/or double-stranded, and has been assessed by several methods: SCSA (Sperm chromatin structure assay), SCD (Sperm chromatin dispersion test), TUNEL (deoxynucleotidyl-transferase-mediated-dUTP -nick-end-labeling) (Evenson et al., 1980; Gorczyca et al., 1993; Fernández et al., 2005). In our experience, and in the literature, there is vast evidence that the TUNEL technique is presented as a valuable tool for clinical use in infertility (Sakkas \& Alvarez, 2010; Sergerie et al., 2005; Greco et al., 2005; Avendaño et al., 2009).

It has been reported that DNA fragmentation events may be associated with sperm apoptosis (Wu et al., 2009; Sakkas et al., 2002, 2003; Oehninger et al., 2003; Singh et al., 2003). Regarding to this, apoptotic markers have been detected in human spermatozoa, as: externalization of phosphatidylserine, active caspase 3, etc. (Almeida et al., 2009; Kotwicka et al., 2008; Paasch et al., 2004; Shen et al., 2002). On the other hand, some authors have stated that there is a positive correlation between DNA fragmentation and the presence of nuclear vacuoles, especially those that occupy more than $50 \%$ of the nuclear surface (Franco Jr et al., 2008; Nadalini et al., 2009; Oliveira et al., 2010). We have previously reported that in a population of high levels of sperm DNA fragmentation, there is no difference between the proportions of vacuolated spermatozoa (Alvarez Sedó et al., 2011). On the other hand, other reports state that the presence of vacuoles could be associated to the state and/or abnormalities of the acrosome and, thus, not necessarily with DNA fragmentation (Perdrix et al., 2011; Kacem et al., 2010).

Several sperm selection techniques have been proposed with the idea of removing sperm with damaged DNA and/or presence of nuclear vacuoles, in that sense and in our experience, both, Annexin $\mathrm{V}$ columns and IMSI (intracytoplasmic morphologically selected sperm injection) respectively, would be the techniques proposed for this purpose. However, to be possible (according to the authors mentioned above) that both events (DNA fragmentation and vacuoles) represent "the same" or could be related, there may not be a clear indication for both techniques. It is for this reason that this study aims to assess the presence, quantity and size of nuclear vacuoles and their association with DNA damage and chromatin status in sperm samples of men who underwent to assisted reproduction treatments.

\section{MATERIAL AND METHODS \\ Population}

For the present study, a total population of 46 males who underwent to assisted reproductive technology (ART) was considered. According to their latest semen analysis (no longer than three months), were grouped into: (A) 26 patients who had strict morphology index $\leq 4 \%$ and (B) 20 
Figure 1. Left: IMSI-MSOME inverted microscope. Right: Patterns assessed by MSOME.
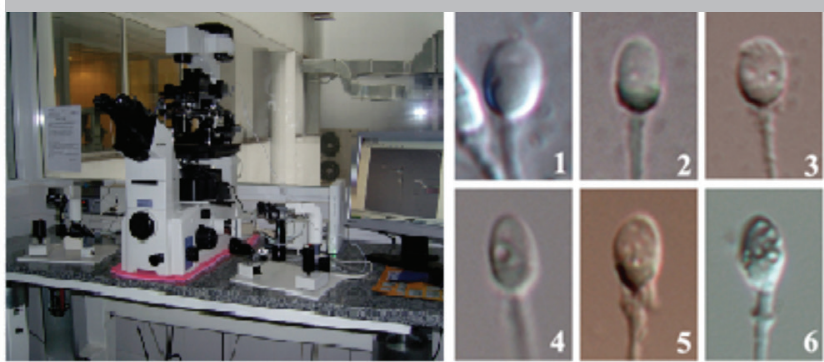

Figure 2. Incubation and detection system in multiwell glass slide for $A O$ and TUNEL assessment.

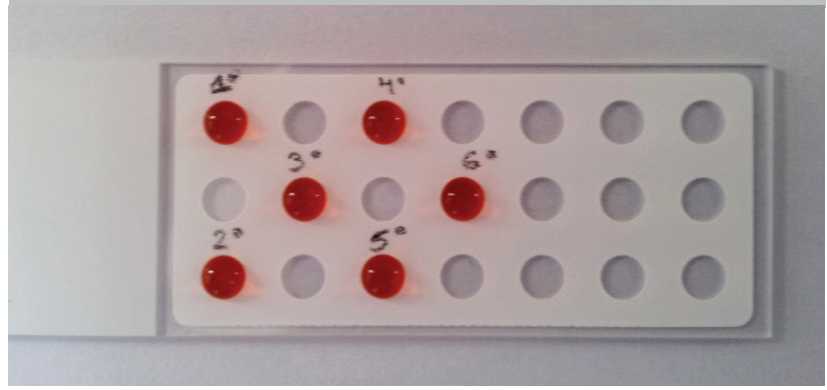

Figure 3. TUNEL assay for DNA fragmentation assessment. Fluorescence $488 \mathrm{~nm}$, positive TUNEL (green) bright field.

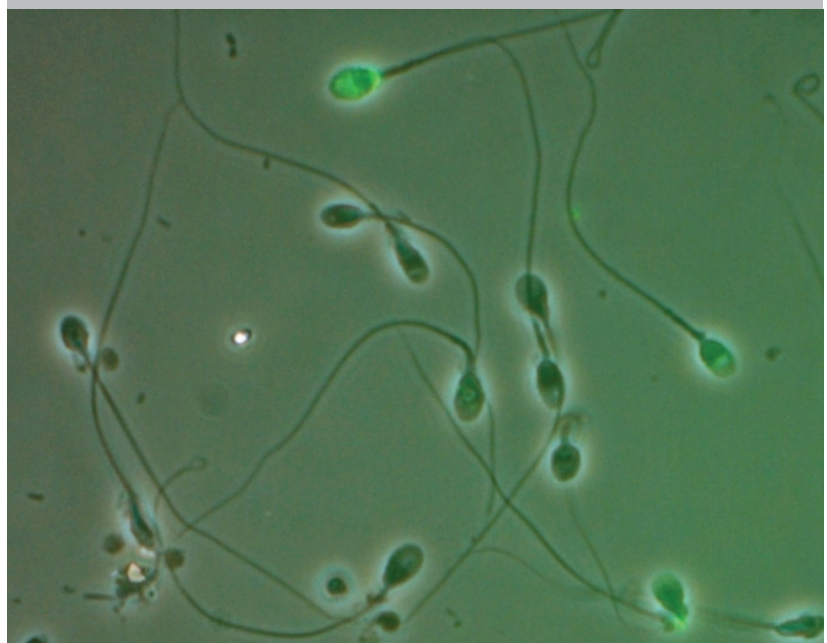

Figure 4. Acridine Orange test. Green sperm (normal), Yellow and Red (affected spermatozoa).

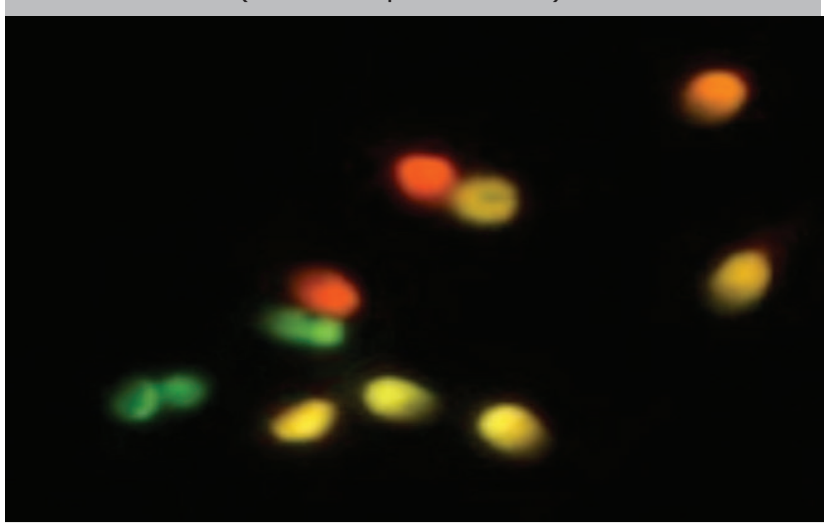

patients with strict morphology index $\geq 14 \%$. In all cases, sperm concentration was $>10 \times 10^{6} / \mathrm{mL}$ and progressive motility $>32 \%$.

\section{Sample preparation}

The samples were evaluated and subjected to discontinuous density gradient separation (PureCeption, SAGE) according to the World Health Organization (WHO, 2010) guidelines.

\section{Sperm vacuoles assessment and selection (MSOME)}

The sperm vacuole assessment was performed using an inverted microscope (Nikon - Eclipse TE 200U. - Differential phase contrast (DIC) and a 100X objective immersion. Therefore a secondary magnification system was used to get a final magnification of 7600X. Figure 1 depicts the patterns considered to assess the number and size of nuclear vacuoles. After identifying each pattern, we proceeded to select (by micro-manipulation) different sperm populations. Each group of sperm was subsequently subjected to the evaluation of DNA fragmentation and acridine orange stain.

\section{Sperm DNA fragmentation (TUNEL)}

Some spermatozoa, from each group, were loaded into a multi-well glass slide (Figure 2), and previously embedded in Poly-L-Lysine for 5 minutes. After that, $20 \mu \mathrm{L}$ of $2 \%$ of formaldehyde in PBS was added in order to fix the cells for a period of 1 hour. The samples were washed with PBS and permeabilized with cold methanol for 3 minutes. It was then incubated with TUNEL solution (Roche) for 1 hour at $37^{\circ} \mathrm{C}$, then washed and mounted with Vectashield $\mathrm{H}-1000$ (Vector Laboratories). The observed patterns are represented in Figure 3.

\section{Acridine Orange stain (AO)}

The AO assay measures the susceptibility of sperm nuclear DNA to acid-induced denaturation in situ by quantifying the metachromatic shift of $A O$ fluorescence from green (native DNA) to red (denatured DNA). The fluorochrome AO intercalates into double-stranded DNA as a monomer and binds to single-stranded DNA as an aggregate.

The monomeric AO bound to native DNA fluorescence green, whereas the aggregated $\mathrm{AO}$ on denatured DNA fluoresces red (Figure 4). For the procedure, spermatozoa were loaded into the multi well glass slide and let them dry. Starting from a stock solution of AO $1 \%$, a working solution was prepared with $0.1 \mathrm{M}$ of citric acid, $0.3 \mathrm{M}$ of $\mathrm{Na} 2 \mathrm{HPO} 47 \mathrm{H} 2 \mathrm{O}$ at $\mathrm{pH}$ 2.5. Samples were fixed with Carnoy's solution for 1-2hs. Sample were carefully washed with distilled water, then stained with $\mathrm{AO}$ solution for 5

Table 1. Acridine Orange and TUNEL levels in group A patients.

\section{Markers at Group A}

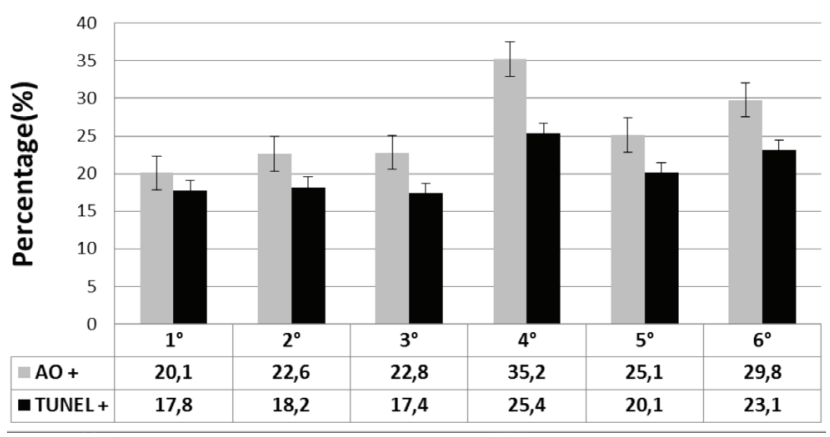


Table 2. Acridine Orange and TUNEL levels in group B patients.

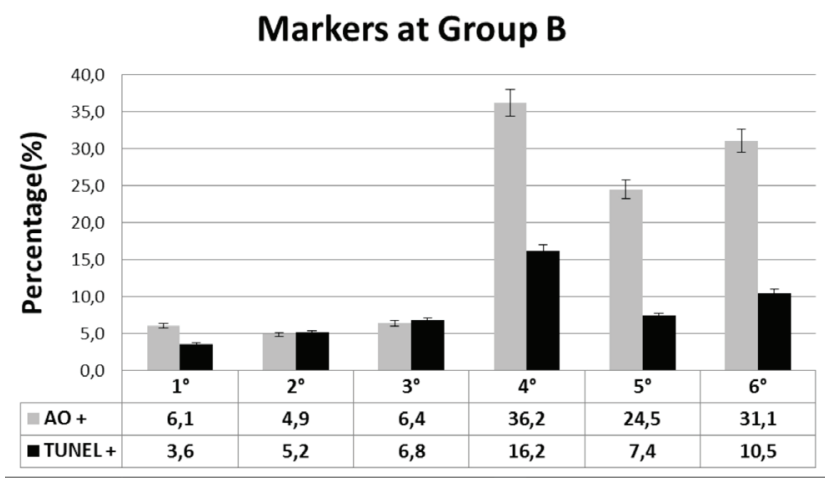

Table 3. Comparisson between Group A vs. B (TUNEL).

TUNEL : Group A vs. Group B

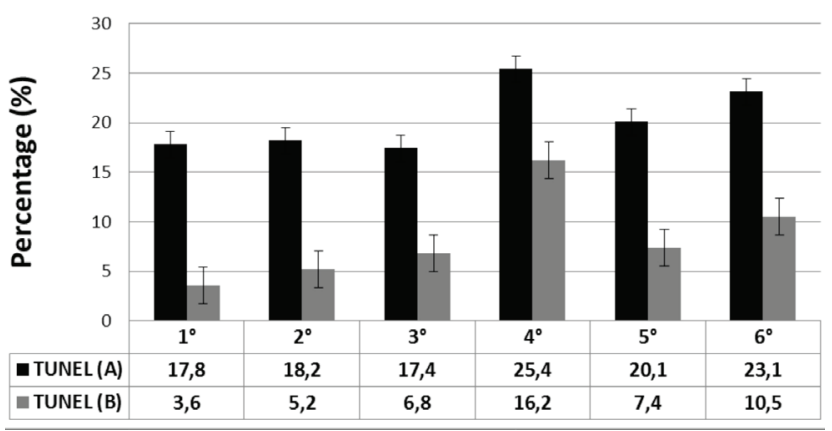

minutes and finally rinsed with distilled water. Immediately the samples were mounted and observed under Fluorescence Microscopy.

\section{Statistics}

The Student's t-test was used for between-group comparisons, and the Mann-Whitney U-test was used to assess homogeneity. Differences were considered significant when $P<0.05$. MedCalc 12.4 software (Belgium) was used for the statistical analysis.

\section{RESULTS}

Table 1 shows the averages of Acridine Orange and TUNEL in group A (558 sperm evaluated). All spermatozoa were grouped according to stablished vacuole patterns. In this group of patients can be observed that sperm without vacuoles $\left(1^{\circ}\right)$ have similar levels of DNA fragmentation by TUNEL in compare to the rest of observed patterns $\left(2^{\circ}\right.$ $\left.6^{\circ}\right)$, although it is true, the patterns 4,5 and 6 show a slightly increase of TUNEL, but these are not statistically significant. Regarding to $\mathrm{AO}$, it 's clearly seen that spermatozoa with large or several vacuoles that cover more than $30-50 \%$ of the nuclear surface are AO+ $(P<0.05)$, but not necessarily TUNEL positive. The first three patterns of vacuoles patterns had lower levels of $\mathrm{AO}$ in compare to grades $4^{\circ}$ and $6^{\circ}(P<0.05)$.

Moreover, in Table 2, corresponding to the group B (380 sperm evaluated). Unlike the previous group, those sperm with one or more vacuoles greater than 30\%-50\% ( $4^{\circ}$ and $\left.6^{\circ}\right)$, had a significant increase in TUNEL values, in relation to group $1^{\circ}-3^{\circ}(P<0.05)$. Regarding the $A O$, it was found that the pattern $4^{\circ}$ and $6^{\circ}$ had a significantly elevated level of this marker, as same of group $A(P<0.05)$.

Table 3 shows the comparison of TUNEL values between the groups $\mathrm{A}$ and $\mathrm{B}$, demonstrating in all vacuoles patterns, even 1 , an increase is observed $(P<0.05)$ in group $A$. In both groups pattern $4^{\circ}$ had the higher level of DNA damage $(P<0.05)$.

\section{DISCUSSION}

It has been described, in recent reports, the possible positive correlation between higher rates of sperm DNA fragmentation and the presence of larger nuclear vacuoles (4th pattern) (Franco Jr et al., 2008; Nadalini et al., 2009; Oliveira et al., 2010). In these cited papers, there is no specification of what type of patients was used for the study, i.e., not previously identified populations. By contrast, in our experience, the experimental design was created to identify the population that could benefit from the techniques of sperm selection here proposed. In our results, in a population with an altered morphology (Kruger $<4 \%$ ) and elevated levels of DNA fragmentation, an indistinct presence of sperms with size-number of vacuoles was observed, normal spermatozoa had the same proportion of DNA damage that those sperm with different vacuole patterns. These results are in accordance with those previously described by our group, where in a population enriched with apoptotic sperm and morphology $<4 \%$, no differences in sperm counts with or without vacuoles were observed, regarding the non-apoptotic population of the same sample (Alvarez Sedó et al., 2011). On the other hand, it is important to mention that this work confirms that patients with morphology index $<4 \%$ present a higher proportion of DNA fragmentation levels compared to patients with morphology index $>14 \%$; in previous reports from our group this increase was further defined as/when age is greater $40-45$ years (Uriondo et al., 2011).

By contrast, in a population of spermatozoa with normal morphology (Kruger $\geq 14 \%$ ), morphologically normal sperm or with small vacuoles compromising less than $20 \%$ of its nucleus surface, exhibit a significantly lower proportion of DNA damage compared to sperm with 4th or 6th patterns, ie, one or more vacuoles representing $30-50 \%$ of the nuclear surface, which would coincide with that reported by previously mentioned authors.

In this sense, we can say that IMSI technique for selecting non-fragmented sperm in a group of patients with lower than $4 \%$ of morphology index and high levels of fragmentation, taking into account the vacuole pattern, would not be ensuring such purpose. Moreover, even considering the possibility of finding normal spermatozoa in these samples is low; still, they can be equally fragmented. Nonetheless, in patients with normal morphology, selection of morphologically normal sperm or those with small vacuoles (representing less than $20 \%$ of the nuclear surface) could help to select sperm with non-fragmented DNA.

We are aware that further work is needed (e.g, what happens in patients with Kruger 5-13\%), however, we believe so far that our results reveal that in patients with severe alterations in sperm morphology, there would be no predominance of sperm larger-number vacuoles with high spermatic apoptosis. Probably these patients would not benefit "at all" with the election of spermatozoa selected through higher magnification with the purpose of choosing non-fragmented sperm.

\section{CONCLUSION}

There is no relationship between the greater number and size of sperm vacuoles with high levels of DNA fragmentation in patients with severe teratozoospermia (Kruger less 4\%). Conversely, this relationship is evident in normal semen samples (normal morphology. Sperm selection by IMSI technique, to select non-fragmented sperm in patients with Kruger $<4 \%$, is not nec- 
essarily secured when non-vacuolated sperm is selected.

\section{CONFLICT OF INTERESTS}

No conflict of interest have been declared.

\section{Corresponding author:}

Cristian Alvarez Sedó

Centro de Estudios en Genética y Reproducción (CEGYR)

Viamonte 1438, C1055ABB, Buenos Aires, Argentina

E-mail: calvarez@cegyr.com

\section{REFERENCES}

Aitken RJ, Bennetts LE, Sawyer D, Wiklendt AM, King BV. Impact of radio frequency electromagnetic radiation on DNA integrity in the male germline. Int J Androl. 2005; 28:171-9.

Aitken RJ, Wingate JK, De Iuliis GN, Koppers AJ, McLaughlin EA. Cis-unsaturated fatty acids stimulate reactive oxygen species generation and lipid peroxidation in human spermatozoa. J Clin Endocrinol Metab. 2006; 91:4154-63.

Aitken RJ, De Iuliis GN. Origins and consequences of DNA damage in male germ cells. Reprod Biomed Online. 2007; $14: 727-33$

Aitken RJ, De Iuliis GN, McLachlan RI. Biological and clinical significance of DNA damage in the male germ line. Int J Androl. 2009; 32:46-56.

Almeida C, Sousa M, Barros A. Phosphatidylserine translocation in human spermatozoa from impaired spermatogenesis. Reprod Biomed Online. 2009; 19:770-7.

Alvarez Sedó C, Lavolpe M, Uriondo H, Papier S, Nodar F, Chillik C. [Nuclear vacuoles and apoptosis markers in patients with teratozoospermia]. JBRA Assist Reprod. 2011;15:10-4.

Angelopoulou R, Plastira K, Msaouel P. Spermatozoal sensitive biomarkers to defective protaminosis and fragmented DNA. Reprod Biol Endocrinol. 2007; 5:36.

Avendaño C, Franchi A, Taylor S, Morshedi M, Bocca S, Oehninger S. Fragmentation of DNA in morphologically normal human spermatozoa. Fertil Steril. 2009; 91:107784.

Banks S, King SA, Irvine DS, Saunders PT. Impact of a mild scrotal heat stress on DNA integrity in murine spermatozoa. Reproduction. 2005; 129:505-14.

Carrell DT, Liu L, Peterson CM, Jones KP, Hatasaka $\mathrm{HH}$, Erickson L, Campbell B. Sperm DNA fragmentation is increased in couples with unexplained recurrent pregnancy loss. Arch Androl. 2003; 49:49-55.

Delbes G, Hales BF, Robaire B. Effects of the chemotherapy cocktail used to treat testicular cancer on sperm chromatin integrity. J Androl. 2007; 28:241-9.

Evenson DP, Darzynkiewicz Z, Melamed MR. Relation of mammalian sperm chromatin heterogeneity to fertility. Science. 1980; 210:1131-3.

Fernández JL, Muriel L, Goyanes V, Segrelles E, Gosálvez J, Enciso M, LaFromboise M, De Jonge C. Simple determination of human sperm DNA fragmentation with an improved sperm chromatin dispersion test. Fertil Steril. $2005 ; 84: 833-42$.
Franco JG Jr, Baruffi RL, Mauri AL, Petersen CG, Oliveira JB, Vagnini L. Significance of large nuclear vacuoles in human spermatozoa: implications for ICSI. Reprod Biomed Online. $2008 ; 17: 42-5$.

Gorczyca W, Traganos F, Jesionowska H, Darzynkiewicz Z. Presence of DNA strand breaks and increased sensitivity of DNA in situ to denaturation in abnormal human sperm cells: analogy to apoptosis of somatic cells. Exp Cell Res. 1993; 207:202-5.

Greco E, Scarselli F, Iacobelli M, Rienzi L, Ubaldi F, Ferrero S, Franco G, Anniballo N, Mendoza C, Tesarik J. Efficient treatment of infertility due to sperm DNA damage by ICSI with testicular spermatozoa. Hum Reprod. 2005; 20:226-30.

Kacem O, Sifer C, Barraud-Lange V, Ducot B, De Ziegler D, Poirot C, Wolf J. Sperm nuclear vacuoles, as assessed by motile sperm organellar morphological examination, are mostly of acrosomal origin. Reprod Biomed Online. 2010; 20:132-7.

Kotwicka M, Filipiak K, Jedrzejczak P, Warchol JB. Caspase-3 activation and phosphatidylserine membrane translocation in human spermatozoa: is there a relationship? Reprod Biomed Online. 2008; 16:657-63.

Lewis SE, Aitken RJ. DNA damage to spermatozoa has impacts on fertilization and pregnancy. Cell Tissue Res. $2005 ; 322: 33-41$.

Mehdi M, Khantouche L, Ajina M, Saad A. Detection of DNA fragmentation in human spermatozoa: correlation with semen parameters. Andrologia. 2009; 41:383-6.

Meseguer M, Martínez-Conejero JA, O'Connor JE, Pellicer A, Remohí J, Garrido N. The significance of sperm DNA oxidation in embryo development and reproductive outcome in an oocyte donation program: a new model to study a male infertility prognostic factor. Fertil Steril. 2008; 89:1191-9.

Moskovtsev SI, Willis J, White J, Mullen JB. Sperm DNA damage: correlation to severity of semen abnormalities. Urology. 2009; 74:789-93.

Nadalini M, Tarozzi N, Distratis V, Scaravelli G, Borini A. Impact of intracytoplasmic morphologically selected sperm injection on assisted reproduction outcome: a review. Reprod Biomed Online. 2009; 19:45-55.

Oehninger S, Morshedi M, Weng SL, Taylor S, Duran H, Beebe S. Presence and significance of somatic cell apoptosis markers in human ejaculated spermatozoa. Reprod Biomed Online. 2003; 7:469-76.

Oliveira JB, Massaro FC, Baruffi RL, Mauri AL, Petersen CG, Silva LF, Vagnini LD, Franco JG Jr. Correlation between semen analysis by motile sperm organelle morphology examination and sperm DNA damage. Fertil Steril. 2010; 94:1937-40.

Paasch U, Grunewald S, Agarwal A, Glandera HJ. Activation pattern of caspases in human spermatozoa. Fertil Steril. $2004 ; 81: 802-9$.

Perdrix A, Travers A, Chelli MH, Escalier D, Do Rego JL, Milazzo JP, Mousset-Siméon N, Macé B, Rives N. Assessment of acrosome and nuclear abnormalities in human spermatozoa with large vacuoles. Hum Reprod. 2011; 26: 47-58. 
Sakkas D, Moffatt O, Manicardi GC, Mariethoz E, Tarozzi $\mathrm{N}$, Bizzaro D. Nature of DNA damage in ejaculated human spermatozoa and the possible involvement of apoptosis. Biol Reprod. 2002; 66:1061-7.

Sakkas D, Seli E, Bizzaro D, Tarozzi N, Manicardi GC. Abnormal spermatozoa in the ejaculate: abortive apoptosis and faulty nuclear remodelling during spermatogenesis. Reprod Biomed Online. 2003; 7:428-32.

Sakkas D, Alvarez JG. Sperm DNA fragmentation: mechanisms of origin, impact on reproductive outcome, and analysis. Fertil Steril. 2010; 93:1027-36.

Seli E, Gardner DK, Schoolcraft WB, Moffatt O, Sakkas D. Extent of nuclear DNA damage in ejaculated spermatozoa impacts on blastocyst development after in vitro fertilization. Fertil Steril. 2004; 82:378-83.

Sergerie M, Laforest G, Bujan L, Bissonnette F, Bleau G. Sperm DNA fragmentation: threshold value in male fertility. Hum Reprod. 2005; 20:3446-51.

Shen HM, Dai J, Chia SE, Lim A, Ong CN. Detection of apoptotic alterations in sperm in subfertile patients and their correlations with sperm quality. Hum Reprod. 2002; 17:1266-73.

Singh NP, Muller $\mathrm{CH}$, Berger RE. Effects of age on DNA double-strand breaks and apoptosis in human sperm. Fertil Steril. 2003; 80:1420-30.

Smit M, van Casteren NJ, Wildhagen MF, Romijn JC,
Dohle GR. Sperm DNA integrity in cancer patients before and after cytotoxic treatment. Hum Reprod. 2010; 25: 1877-83.

Smith R, Kaune H, Parodi D, Madariaga M, Morales I, Ríos $\mathrm{R}$, Castro A. [Extent of sperm DNA damage in spermatozoa from men examined for infertility. Relationship with oxidative stress]. Rev Med Chil. 2007; 135: 279-86.

Uriondo H, Alvarez Sedó C, Gil Ma. Virginia, Frazer P, Serna J, Nodar F. [Correlation between phosphatidylserine externalization and sperm apoptosis in infertile men]. Reproducción 2011; 26: 111-6.

Vagnini L, Baruffi RL, Mauri AL, Petersen CG, Massaro FC, Pontes A, Oliveira JB, Franco JG Jr. The effects of male age on sperm DNA damage in an infertile population. Reprod Biomed Online. 2007; 15:514-9.

Virro MR, Larson-Cook KL, Evenson DP. Sperm chromatin structure assay (SCSA) parameters are related to fertilization, blastocyst development, and ongoing pregnancy in in vitro fertilization and intracytoplasmic sperm injection cycles. Fertil Steril. 2004; 81:1289-95.

World Health Organization. WHO laboratory manual for the Examination and processing of human semen.5th ed. WHO Press Health Organization, 20, Switzerland. 2010.

Wu GJ, Chang FW, Lee SS, Cheng YY, Chen $\mathrm{CH}$, Chen IC. Apoptosis-related phenotype of ejaculated spermatozoa in patients with varicocele. Fertil Steril. 2009; 91: 831-7. 